Relations industrielles

Industrial Relations

\title{
L'apprentissage et les statistiques
}

\section{Charles-E. Thérien}

Volume 6, numéro 1, décembre 1950

URI : https://id.erudit.org/iderudit/1023247ar

DOI : https://doi.org/10.7202/1023247ar

Aller au sommaire du numéro

Éditeur(s)

Département des relations industrielles de l'Université Laval

ISSN

0034-379X (imprimé)

1703-8138 (numérique)

Découvrir la revue

Citer cet article

Thérien, C.-E. (1950). L'apprentissage et les statistiques. Relations industrielles / Industrial Relations, 6(1), 26-27. https://doi.org/10.7202/1023247ar

Tous droits réservés @ Département des relations industrielles de l’Université Laval, 1950
Ce document est protégé par la loi sur le droit d'auteur. L’utilisation des services d'Érudit (y compris la reproduction) est assujettie à sa politique d'utilisation que vous pouvez consulter en ligne.

https://apropos.erudit.org/fr/usagers/politique-dutilisation/ 
ridictions et par quelles procédures on peut attaquer les décisions de la Commission de relations ouvrières. Quand la Commission peut-elle \& pour cause, reviser ou révoquer toute décision et tout ordre rendus par elle et tout certificat qu'elle a émis », comme dit l'article 41 de la Loi des relations ouvrières ? La Commission a-t-elle une autre juridiction que celle que lui donne cet article ? Nous examinerons le recours par voie de certiorari, refusé par l'honorable juge Edge; le bref d'injonction, écarté par l'honorable juge J.-Oscar Boulanger; le jugement qu'aura rendu la Cour d'appel sur le bref de prohibition maintenu par l'honorable juge Alfred Savard.

Voilà autant de questions très intéressantes et très pratiques pour les avocats, pour les officiers de syndicats ouvriers ou d'associations patronales, pour les employeurs, pour les fonctionnaires publics, pour tous ceux qui s'occupent des relations patronales-ouvrières.

\section{L'apprentissage et les statistiques}

Charles-E. Thérien,

\section{statisticien à la Commission d'apprentissage des métiers du bâtiment de Montréal}

La loi de l'Aide à l'apprentissage de la Province de Québec sanctionnée le 24 mai 1945 préconise une formule d'apprentissage des plus intéressantes. Sa valeur, il n'y a pas de doute, vient du fait qu'elle prend sa source dans la collaboration tripartite du Capital, du Travail et de l'Etat. Cette formule qui laisse à l'industrie la direction de l'apprentissage sous la surveillance de l'Etat a déjà fait ses preuves.

En effet, en moins de deux ans plus de quinze Commissions d'apprentissage furent constituées dans tous les coins de la Province. Des Centres d'apprentissage furent ouverts et l'on commença l'entraînement des apprentis.

Dans la seule région de Montréal, la Commission d'apprentissage des Métiers du Bâtiment a entraîné à divers degrés, depuis l'ouverture de son centre, au delà de 3,500 apprentis et compagnons. Le tableau cidessous illustre de façon concrète les activités de ce centre.

Il est donc facile de constater que le système d'apprentissage de la Province a déjà porté des fruits dont il faut se réiouir. Cependant il y a possibilité de lui faire rendre davantage en le perfectionnant. Une entrave au perfectionnement de ce système aujourd'hui, c'est le manque de statistiques, le manque de données essentielles.

Pour orienter de facon rationnelle les apprentis, il faut connaître, du point de vue statistique, d'abord, les besoins de l'industrie, en ce qui concerne la main-d'oeuvre et, en second lieu, le nombre d'apprentis entraînés dans les centres.

En partant de ces données essentielles, il sera infiniment plus facile de développer un programme d'entraînement pour les apprentis, selon une politique basée sur les besoins réels de l'industrie et sur la connaissance exacte des possibilités de rendement des centres d'apprentissage.

Il est donc urgent que ceux qui se préoccupent du problème de l'apprentissage collaborent activement dans ce domaine. Il est bien important que les employeurs et les chefs d'unions aussi bien que les membres des commissions d'apprentissage et des comités paritaires intéressés se fassent un devoir d'alimenter les divers bureaux de statistiques des chiffres essentiels à la cause de l'apprentissage. En agissant ainsi, tous aideront effectivement à son perfectionnement.
Il faut que les Sociétés soient devenues bien maladroites et les doctrinaires bien inhumains pour en arriver d dégoúter les hommes de leur travail. C'est un sentiment si naturel de s'attacher d ce qu'on fait. Maurois (Art de vivre)
La psychologie devra aider à opérer dans lorganisation du travail une transformation capitale qui consistera d faire passer l'ouvrier de lobéissance passive d la collaboration spontanée.

H. Dubreuil

(La chevalerie du travail) 


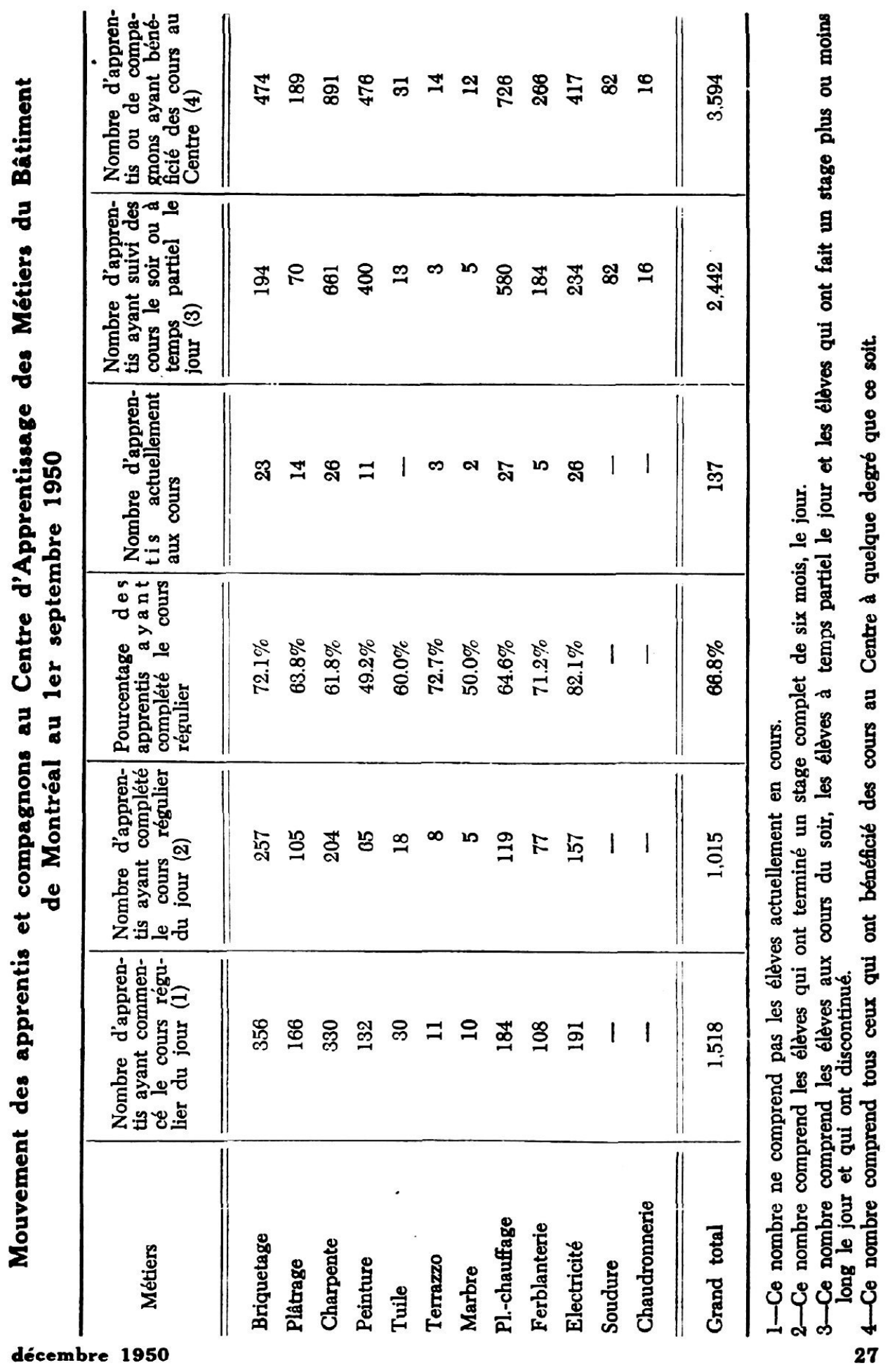

